\title{
The Role of Oxygen-Derived Free Radicals in Augmented Relaxations to Levcromakalim in the Aorta From Hypertensive Rats
}

\author{
Hiroyuki Kinoshita ${ }^{1, *}$, Tetsuya Kakutani ${ }^{2}$, Hiroshi Iranami ${ }^{1}$ and Yoshio Hatano ${ }^{2}$ \\ ${ }^{1}$ Department of Anesthesia, Japanese Red Cross Society Wakayama Medical Center, \\ 4-20 Komatsubara-dori, Wakayama 640-8269, Japan \\ ${ }^{2}$ Department of Anesthesiology, Wakayama Medical Collage, Wakayama 641-0012, Japan
}

Received July 5, 2000 Accepted September 25, 2000

\begin{abstract}
Hydrogen peroxide and peroxynitrite induce relaxations via ATP-sensitive $\mathrm{K}^{+}$channels, indicating that oxygen-derived free radicals may activate these channels. Levels of free radicals are increased throughout the arterial wall in animal models of atherosclerosis, and therefore, vasorelaxation via ATPsensitive $\mathrm{K}^{+}$channels may be augmented in chronic hypertension. The present study was designed to determine whether relaxations to an ATP-sensitive $\mathrm{K}^{+}$channel opener, levcromakalim, are increased in the aorta from spontaneously hypertensive rats (SHR) and whether free radical scavengers reduce these relaxations. Rings of aortas without endothelium taken from age-matched Wistar-Kyoto rats (WKY) and SHR were suspended for isometric force recording. Relaxations to levcromakalim $\left(10^{-8}\right.$ to $\left.10^{-5} \mathrm{M}\right)$, which are abolished by glibenclamide $\left(10^{-5} \mathrm{M}\right)$, were augmented in the aorta from SHR, compared to those in the aorta from WKY. In the aorta from SHR, catalase $(1200 \mathrm{U} / \mathrm{ml})$, but neither superoxide dismutase $(150 \mathrm{U} / \mathrm{ml})$ nor deferoxamine $\left(10^{-4} \mathrm{M}\right)$, reduced relaxations to levcromakalim, whereas in the aorta from WKY, the free radical scavengers did not affect these relaxations. These results suggest that in chronic hypertension, vasorelaxation to an ATP-sensitive $\mathrm{K}^{+}$channel opener is augmented and that hydrogen peroxide produced in smooth muscle cells may partly contribute to these relaxations.
\end{abstract}

Keywords: ATP-sensitive $\mathrm{K}^{+}$channel, Catalase, Glibenclamide, Hydrogen peroxide

Hydrogen peroxide and peroxynitrite can induce relaxations via ATP-sensitive $\mathrm{K}^{+}$channels in cerebral arterioles (1). A recent study in cerebral blood vessels has also demonstrated that non-selective free radical scavengers, such as salicylate and L-cysteine, inhibit vasodilation induced by ATP-sensitive $\mathrm{K}^{+}$channel openers, cromakalim and pinacidil (2). In cardiac myocytes, ATP-sensitive $\mathrm{K}^{+}$channel currents produced by the reaction between xanthine and xanthine oxidase, are abolished by superoxide dismutase and catalase (3). These results suggest that in these preparations, oxygen-derived free radicals may play a role in activation of ATP-sensitive $\mathrm{K}^{+}$channels. Recent studies have demonstrated increased levels of oxygen-derived free radicals throughout the wall of arteries taken from animal models of atherosclerosis (4). Therefore, in atherosclerotic blood vessels, vasorelaxation via ATP-sensitive $\mathrm{K}^{+}$channels may be augmented by the increased production of these radicals. Since ATP-sensitive $\mathrm{K}^{+}$channel openers can be used as vasodilators for the treatment of cardiovascular

*Corresponding author. FAX: +81-73-426-1168

E-mail: hkinoshi@pd5.so-net.ne.jp disorders, it is crucial to determine whether vasodilator effects induced by these openers are modified in chronic hypertension, which can progressively aggravate atherosclerotic lesions in the arterial walls (5). Indeed, a recent study demonstrated that relaxations to ATP-sensitive $\mathrm{K}^{+}$ channel openers are augmented in arteries from hypertensive rats, compared to those from normotensive rats (6). However, the role of oxygen-derived free radicals in augmented relaxations to ATP-sensitive $\mathrm{K}^{+}$channel openers in chronic hypertension has not been studied.

Levcromakalim is one of the currently available ATPsensitive $\mathrm{K}^{+}$channel openers, and it produces potent and selective vasodilator effects via these channels $(7,8)$. The clinically relevant concentrations of this ATP-sensitive $\mathrm{K}^{+}$ channel opener may induce the augmented vasodilation in hypertensive animals. Therefore, the present study was designed to examine the mechanisms of augmented relaxations to an ATP-sensitive $\mathrm{K}^{+}$channel opener in chronic hypertension by determining in the aorta from hypertensive rats, whether relaxations to levcromakalim are increased and whether oxygen-derived free radical scavengers reduce these relaxations. 


\section{MATERIALS AND METHODS}

The study was approved by the institutional animal care and use committee. Male age-matched Wistar-Kyoto rats (WKY) and spontaneously hypertensive rats (SHR) (16 to 18 weeks of age) were obtained from Charles River Japan, Inc. (Yokohama). Rats were anesthetized with inhalation of $1 \%$ halothane, and systemic blood pressure at the abdominal aorta was measured by cannulating from the femoral artery with the $24 \mathrm{G}$ Teflon catheter, connecting it to the pressure transducer and this in turn to a recorder (RMC1100; Nihon Kohden Inc., Tokyo). Mean arterial pressure was greater in SHR compared to WKY (141 \pm 10 vs $89 \pm 5 \mathrm{mmHg}, P<0.05)$, whereas heart rate did not significantly differ $(280 \pm 19$ vs $273 \pm 22 \mathrm{bpm}$, NS). After these measurements, the rats were sacrificed by exanguination and thoracic aortas were harvested. Thoracic aortic rings of $3 \mathrm{~mm}$ in length were studied in modified Krebs-Ringer bicarbonate solution (control solution) of the following composition: $119 \mathrm{mM} \mathrm{NaCl}, 4.7 \mathrm{mM} \mathrm{KCl}, 2.5 \mathrm{mM} \mathrm{CaCl}_{2}$, $1.17 \mathrm{mM} \mathrm{MgSO}_{4}, 1.18 \mathrm{mM} \mathrm{KH}_{2} \mathrm{PO}_{4}, 25 \mathrm{mM} \mathrm{NaHCO}_{3}$ and $11 \mathrm{mM}$ glucose. In all rings, the endothelium was removed mechanically. Several rings cut from the same artery were studied in parallel. Each ring was connected to an isometric force transducer and suspended in an organ chamber filled with $10 \mathrm{ml}$ control solution $\left(37^{\circ} \mathrm{C}, \mathrm{pH} 7.4\right)$ bubbled with $95 \% \mathrm{O}_{2}-5 \% \mathrm{CO}_{2}$ gas mixture. The artery was gradually stretched to the optimal point of its length-tension curve as determined by the contraction to phenylephrine $\left(3 \times 10^{-7} \mathrm{M}\right)$. In most of the studied arteries, optimal tension was achieved approximately at $1.5 \mathrm{~g}$. The endothelial removal was evaluated by the absence of relaxation induced by acetylcholine $\left(10^{-5} \mathrm{M}\right)$. Preparations were equilibrated for 90 min. During submaximal contractions to phenylephrine $\left(3 \times 10^{-7} \mathrm{M}\right)$, concentration-response curves to levcromakalim $\left(10^{-8}\right.$ to $\left.10^{-5} \mathrm{M}\right)$ were obtained in the absence or in the presence of indomethacin $\left(10^{-5} \mathrm{M}\right)$, superoxide dismutase (SOD, $150 \mathrm{U} / \mathrm{ml})$, catalase $(1200 \mathrm{U} / \mathrm{ml})$, deferoxamine $\left(10^{-4} \mathrm{M}\right)$, glibenclamide $\left(10^{-5} \mathrm{M}\right)$. Concentrationresponse curves were obtained in a cumulative fashion. Only one concentration-response curve was made from each ring. SOD and catalase, deferoxamine and glibenclamide, and indomethacin were given 5,15 or $30 \mathrm{~min}$ before addition of phenylephrine $\left(3 \times 10^{-7} \mathrm{M}\right)$, respectively. The relaxations were expressed as a percentage of the maximal relaxations to papaverine $\left(3 \times 10^{-4} \mathrm{M}\right)$, which is added at the end of experiments to produce maximal relaxations $(=100 \%)$ of the arteries.

\section{Drugs}

The following pharmacological agents were used: catalase, deferoxamine, glibenclamide, indomethacin, papaverine hydrochloride, phenylephrine, superoxide dismutase (from bovine erythrocytes) (Sigma, St. Louis, MO, USA). Levcromakalim was a generous gift from SmithKline Beecham Pharmaceutical Co. (Betchworth, Surrey, Great Britain). Drugs were dissolved in distilled water such that volumes of $<60 \mu \mathrm{l}$ are added to the organ chambers. Stock solutions of levcromakalim $\left(10^{-5} \mathrm{M}\right)$ was prepared in DMSO $\left(3 \times 10^{-4} \mathrm{M}\right)$. A stock solution of indomethacin $\left(10^{-5} \mathrm{M}\right)$ was prepared in equal molar concentrations of $\mathrm{Na}_{2} \mathrm{CO}_{3}$. The concentrations of drugs are expressed as final molar (M) concentration.

\section{Statistical analyses}

The data were expressed as means \pm S.D.; $n$ refers to the number of rats from which the aorta was taken. Statistical analysis was performed by repeated measures ANOVA, followed by Scheffe's $\mathrm{F}$ test for multiple comparison. Differences were considered to be statistically significant when $P$ is $<0.05$.

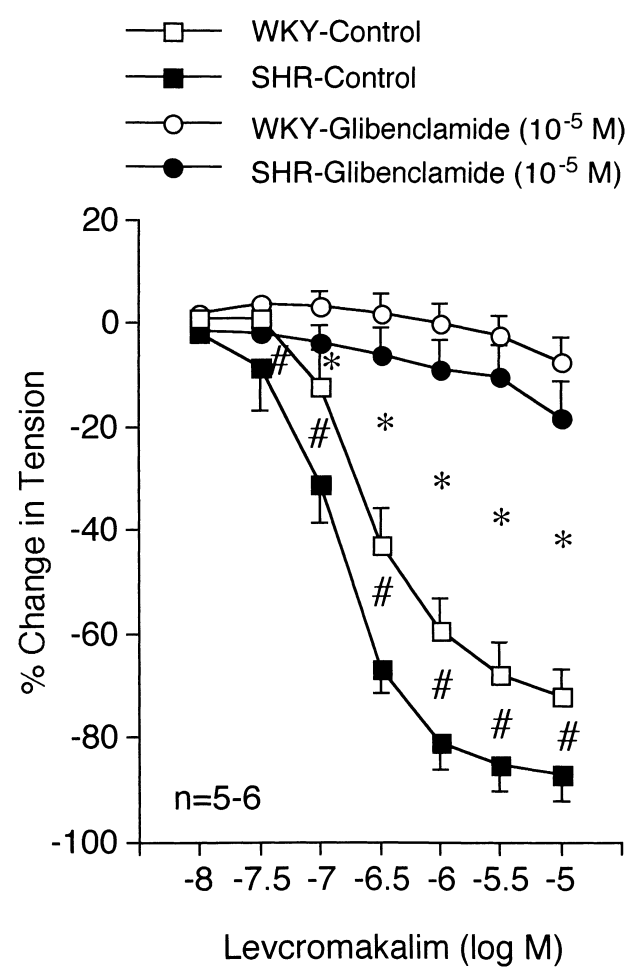

Fig. 1. Concentration-response curves to levcromakalim $\left(10^{-8}\right.$ to $\left.10^{-5} \mathrm{M}\right)$ in the absence and in the presence of glibenclamide $\left(10^{-5} \mathrm{M}\right)$ in the aorta from WKY or SHR, respectively. Data are shown as means \pm S.D. and expressed as a percent of the maximal relaxation induced by papaverine $\left(3 \times 10^{-4} \mathrm{M} ; 100 \%=1277 \pm 163 \mathrm{mg}[\mathrm{n}=6]\right.$ and $1180 \pm 483 \mathrm{mg}[\mathrm{n}=6], 1197 \pm 201 \mathrm{mg}[\mathrm{n}=6]$ and $928 \pm 115 \mathrm{mg}$ $[\mathrm{n}=5$ ] for control rings from WKY and rings from WKY treated with glibenclamide, and control rings from SHR and rings from SHR treated with glibenclamide, respectively). *Difference between control rings and rings treated with glibenclamide and "difference between control rings from WKY and control rings from SHR are statistically significant $(P<0.05)$. 


\section{RESULTS}

During submaximal contractions to phenylephrine $\left(3 \times 10^{-7} \mathrm{M}\right)$, relaxations to levcromakalim $\left(10^{-8}\right.$ to $\left.10^{-5} \mathrm{M}\right)$ were augmented in aortas from SHR, compared to those in the artery from WKY (Fig. 1). The relaxations in both arteries were abolished by a selective ATP-sensitive $\mathrm{K}^{+}$ channel inhibitor, glibenclamide $\left(10^{-5} \mathrm{M}\right)$ (Fig. 1). In aortas from SHR, a hydrogen peroxide scavenger (catalase, $1200 \mathrm{U} / \mathrm{ml}$; Fig. 2a), but neither a superoxide anion scavenger (SOD, $150 \mathrm{U} / \mathrm{ml}$; Fig. 2b) nor a hydroxyl radical scavenger (deferoxamine, $10^{-4} \mathrm{M}$; Fig. 2c), reduced relaxations to levcromakalim. In contrast, in the aorta from WKY, the free radical scavengers did not affect these relaxations (Table 1). In addition, these free radical scavengers did not have any effects on baseline tension in the aorta from hypertensive rats as well as normotensive rats (data not shown). The cyclooxygenase inhibitor indomethacin $\left(10^{-5} \mathrm{M}\right)$ did not alter relaxations to levcromakalim in arteries from SHR (data not shown).

\section{DISCUSSION}

In the present study, relaxations to clinically relevant
Table 1. Effects of catalase $(1200 \mathrm{U} / \mathrm{ml})$, superoxide dismutase (SOD, $150 \mathrm{U} / \mathrm{ml}$ ), and deferoxamine $\left(10^{-4} \mathrm{M}\right)$ on relaxations to levcromakalim in the aorta from Wistar-Kyoto rats

\begin{tabular}{lccc}
\hline & $\mathrm{n}$ & $-\log \mathrm{EC}_{50}$ & $\begin{array}{c}\text { \% of maximal } \\
\text { relaxation }\end{array}$ \\
\hline Control & 6 & $6.61 \pm 0.09$ & $-72.2 \pm 5.3$ \\
Catalase $(1200 \mathrm{U} / \mathrm{ml})$ & 6 & $6.63 \pm 0.06$ & $-74.4 \pm 6.9$ \\
SOD $(150 \mathrm{U} / \mathrm{ml})$ & 6 & $6.71 \pm 0.13$ & $-76.6 \pm 6.3$ \\
Deferoxamine $\left(10^{-4} \mathrm{M}\right)$ & 6 & $6.68 \pm 0.04$ & $-78.7 \pm 5.1$ \\
\hline
\end{tabular}

Data are shown as means \pm S.D.

concentrations of levcromakalim (from $3 \times 10^{-8} \mathrm{M}$ ) were augmented in the aorta from SHR, compared to those in the artery from WKY. Since relaxations to levcromakalim in both arteries were abolished by a selective ATP-sensitive $\mathrm{K}^{+}$channel inhibitor glibenclamide $(9-11)$, our results suggest that in chronic hypertension, vasorelaxation in response to clinically relevant concentrations of an ATP-sensitive $\mathrm{K}^{+}$channel opener is augmented. This conclusion is supported by a recent study demonstrating that relaxations in response to ATP-sensitive $\mathrm{K}^{+}$channel openers other than levcromakalim are augmented in arteries from hypertensive rats, compared to those from normotensive rats (6). a

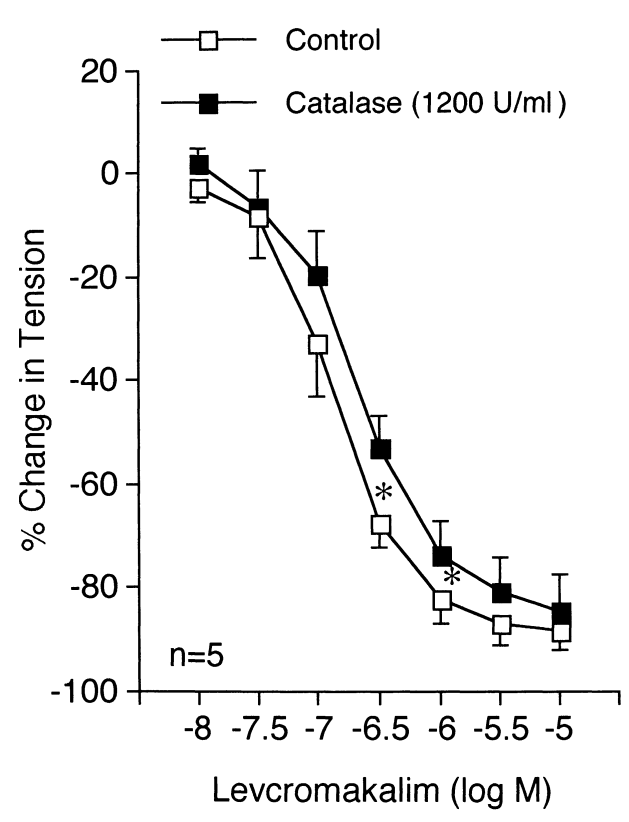

b

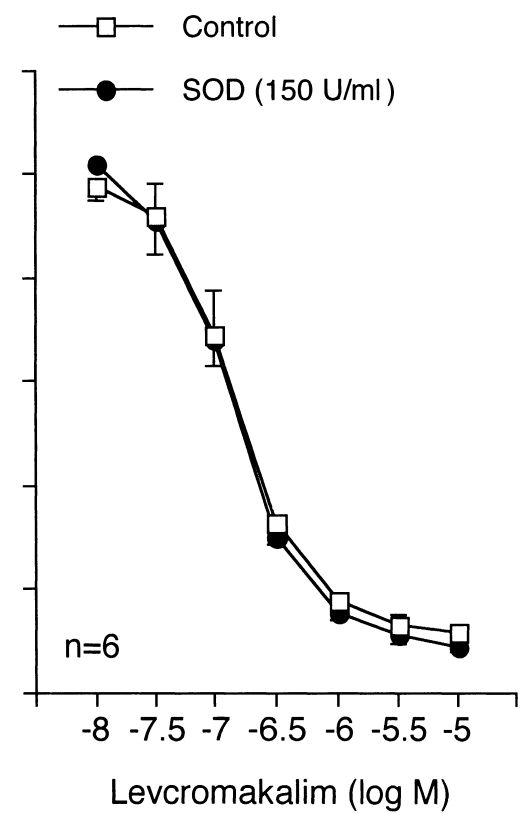

C

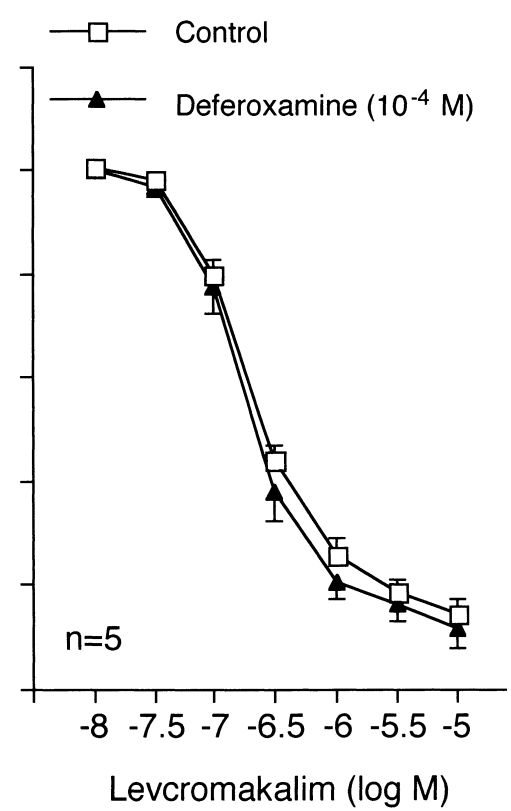

Fig. 2. Concentration-response curves to levcromakalim $\left(10^{-8}\right.$ to $\left.10^{-5} \mathrm{M}\right)$ in the absence and in the presence of catalase $(1200 \mathrm{U} / \mathrm{ml}$, a), superoxide dismutase (SOD, $150 \mathrm{U} / \mathrm{ml}, \mathrm{b})$ or deferoxamine $\left(10^{-4} \mathrm{M}\right.$, c), obtained in the aorta from SHR. Data are shown as means \pm S.D. and expressed as a percent of the maximal relaxation induced by papaverine $\left(3 \times 10^{-4} \mathrm{M}\right.$; $100 \%=1100 \pm 96 \mathrm{mg}[\mathrm{n}=5]$ and $1108 \pm 172 \mathrm{mg}[\mathrm{n}=5], 1130 \pm 113 \mathrm{mg}[\mathrm{n}=6]$ and $1017 \pm 204 \mathrm{mg}[\mathrm{n}=6], 944 \pm 84 \mathrm{mg}[\mathrm{n}=5]$ and $992 \pm 166 \mathrm{mg}[\mathrm{n}=5$ ] for control rings and rings treated with catalase, control rings and rings treated with SOD, and control rings and rings treated with deferoxamine, respectively). ${ }^{*}$ Difference between control rings and rings treated with catalase is statistically significant $(P<0.05)$. 
In the aorta from SHR, catalase reduced relaxations to levcromakalim, indicating that hydrogen peroxide may contribute to relaxations in response to levcromakalim in hypertensive rats $(12,13)$. This conclusion is concurrent with recent studies on blood vessels and renal epithelial cells demonstrating that hydrogen peroxide can induce vasorelaxation or currents via ATP-sensitive $\mathrm{K}^{+}$channels, respectively $(1,14)$. Therefore, it is likely that hydrogen peroxide can activate ATP-sensitive $\mathrm{K}^{+}$channels in these preparations. In the present study, catalase did not have any effects on baseline tension in the aorta from SHR, suggesting that in chronic hypertension, basally released hydrogen peroxide may not play a role in augmented vasorelaxation in response to levcromakalim. Instead, it may be possible that in the aorta from hypertensive rats, levcromakalim itself is capable of activating production of hydrogen peroxide in vascular smooth muscle cells. In addition, we can not completely rule out the possibility that the sensitivity of ATP-sensitive $\mathrm{K}^{+}$channels to hydrogen peroxide is augmented in smooth muscle cells in chronic hypertension. However, molecular mechanisms of the activation of ATPsensitive $\mathrm{K}^{+}$channels induced by this oxygen-derived free radical, remain to be determined. In contrast to the results with catalase, SOD did not reduce relaxations to levcromakalim in the aorta from SHR, suggesting that superoxide anion does not mediate augmented relaxations via ATPsensitive $\mathrm{K}^{+}$channels in chronic hypertension $(12,13)$. Inability of an iron chelator deferoxamine to affect relaxations to levcromakalim indicates that hydroxyl radical may not be a mediator of augmentation of the vasodilator effect via ATP-sensitive $\mathrm{K}^{+}$channels in these arteries (12, 13). In our experimental condition, in the aorta from a normotensive animal, these free radical scavengers did not affect relaxations to levcromakalim. This indicates that in the normotensive rat aorta, oxygen-derived free radicals are not responsible for relaxations via ATP-sensitive $\mathrm{K}^{+}$channels in smooth muscle cells and supports the selectivity of free radical scavengers used in the present study.

A recent study on cultured smooth muscle cells from the rat aorta demonstrated that angiotensin II, which is one of the important vasoconstrictors involved in the pathophysiology of chronic hypertension, mediates production of superoxide anion generated by the NADH/NADPH oxidase, followed by an increase in intracellular levels of hydrogen peroxide (15). It has been also documented that monocytes, which are well known to be capable of producing large amounts of hydrogen peroxide, are present in the aortic wall of hypertensive animals (16). These previous results and ours suggest that in chronic hypertension, hydrogen peroxide contributes to modification of the intracellular redox state of vascular smooth muscle cells. In contrast to these studies, cumulative findings documented the crucial role of superoxide anion in impaired endothelium-de- pendent vasorelaxation in chronic hypertension $(17,18)$. Indeed, in arteries from hypertensive animals, a significant amount of superoxide anion is produced in the presence of endothelium (19). We do not have a clear explanation for why superoxide anions have no role in augmented relaxations to levcromakalim in the present study. However, the present results were obtained in the aorta without endothelium, indicating that at least in our experimental condition, vascular smooth muscle cells may not be responsible for the production of superoxide anions. Previous studies demonstrated that ATP-sensitive $\mathrm{K}^{+}$channels are expressed in endothelial cells as well as smooth muscle cells, suggesting that levcromakalim may also produce activation of these channels on endothelial cells (20). Therefore, precaution may be needed to interpret the role of oxygen-derived free radicals in vasorelaxation mediated by ATP-sensitive $\mathrm{K}^{+}$ channels in hypertensive animals because our results were obtained in preparations without endothelium.

In the aorta from SHR, relaxations in response to levcromakalim were still augmented compared to those in arteries from normotensive animals, even in the presence of catalase. These results suggest that in chronic hypertension, levcromakalim is capable of inducing relaxations via ATPsensitive $\mathrm{K}^{+}$channels in a hydrogen peroxide-independent fashion. It appears that distribution and/or sensitivity of these channels may be increased in this diseased state, resulting in augmented relaxations to levcromakalim. Indeed, increased expression and enhanced sensitivity of $\mathrm{Ca}^{2+}$ dependent $\mathrm{K}^{+}$channels have been demonstrated in arterial smooth muscle cells from SHR $(21,22)$. However, those of ATP-sensitive $\mathrm{K}^{+}$channels have not been determined in chronic hypertension.

Prostanoids play a major role in reduced endotheliumdependent relaxations in animal models of chronic hypertension (23). Therefore, we suspected that prostanoids may contribute to increased relaxations to levcromakalim in chronic hypertension. However, indomethacin did not alter relaxations to levcromakalim in the aorta from SHR, suggesting no role of prostanoids in relaxations to an ATPsensitive $\mathrm{K}^{+}$channel opener in our preparation.

The therapeutic ranges of plasma concentrations of levcromakalim used as an antihypertensive drug, have been reported as $1 \times 10^{-8}$ to $5 \times 10^{-8} \mathrm{M}$, indicating that some concentrations of levcromakalim used in the present study are within plasma concentrations in the clinical situation (unpublished observation by SmithKline Beecham Pharmaceutical Co.). ATP-sensitive $\mathrm{K}^{+}$channel openers are clinically available vasodilators for the treatment of cardiovascular disorders, including hypertension (5). In addition, it has been well-known that in patients with hypertension, endothelium-dependent vasodilation is reduced (24). Therefore, our results indicate that in hypertensive patients, vasodilator effects of ATP-sensitive $\mathrm{K}^{+}$channel openers 
may be augmented and this may be in turn one of the compensatory mechanisms to maintain vasorelaxation in the diseased state where endothelial function is impaired.

\section{Acknowledgments}

This work was supported in part by Grants-in-Aid for Scientific Research from the Ministry of Education, Science, Sports and Culture, Japan. This work was presented in part at the annual meeting of the American Society of Anesthesiologists, Dallas, TX, October 9 13, 1999

\section{REFERENCES}

1 Wei EP, Kontos HA and Beckman JS: Mechanisms of cerebral vasodilation by superoxide, hydrogen peroxide, and peroxynitrite. Am J Physiol 271, H1262 - H1266 (1996)

2 Wei EP, Kontos HA and Beckman JS: Antioxidants inhibit ATP-sensitive potassium channels in cerebral arterioles. Stroke 29, 817 - 823 (1998)

3 Tokube K, Kiyosue T and Arita M: Openings of cardiac $\mathrm{K}_{\text {ATP }}$ channel by oxygen free radicals produced by xanthine oxidase reaction. Am J Physiol 271, H478 - H489 (1996)

4 Miller FJ Jr, Gutterman DD, Rios CD, Heistad DD and Davidson BL: Superoxide production in vascular smooth muscle contributes to oxidative stress and impaired relaxation in atherosclerosis. Circ Res 82, 1289 - 1305 (1998)

5 Cook NS: The pharmacology of potassium channels and their therapeutic potential. Trends Pharmacol Sci 9, $21-28$ (1988)

6 Kwan YW, To KW, Lau WM and Tsang SH: Comparison of the vascular relaxant effects of ATP-dependent $\mathrm{K}^{+}$channel openers on aorta and pulmonary artery isolated from spontaneously hypertensive and Wistar-Kyoto rats. Eur J Pharmacol 365, 241 - 251 (1999)

7 Katnik C and Adams DJ: Characterization of ATP-sensitive potassium channels in freshly dissociated rabbit aortic endothelial cells. Am J Physiol 272, H2507 - H2511 (1997)

8 Kinoshita H, Iwahashi S, Kakutani T, Mizumoto K, Iranami H and Hatano Y: The role of endothelium-derived nitric oxide in relaxations to levcromakalim in the rat aorta. Jpn J Pharmacol 81, 362 - 366 (1999)

9 Meisheri KD, Khan SA and Martin JL: Vascular pharmacology of ATP-sensitive $\mathrm{K}^{+}$channels: interactions between glyburide and $\mathrm{K}^{+}$channel openers. J Vasc Res 30, 2 - 12 (1993)

10 Nelson MT and Quayle JM: Physiological roles and properties of potassium channels in arterial smooth muscle. Am J Physiol 268, C799 - C822 (1995)

11 Kinoshita H, Ishikawa $\mathrm{T}$ and Hatano $\mathrm{Y}$ : Role of $\mathrm{K}^{+}$channels in augmented relaxations to sodium nitroprusside induced by mexiletine in rat aortas. Anesthesiology 92, 813 - 820 (2000)
12 Kinoshita $\mathrm{H}$ and Katusic ZS: Exogenous tetrahydrobiopterin causes endothelium-dependent contractions in isolated canine basilar artery. Am J Physiol 271, H738 - H743 (1996)

13 Kinoshita H, Milstien S, Wambi C and Katusic ZS: Inhibition of tetrahydrobiopterin biosynthesis impairs endothelium-dependent relaxations in canine basilar artery. Am J Physiol 273, H718 H724 (1997)

14 Filipovic DM and Reeves WB: Hydrogen peroxide activates glibenclamide-sensitive $\mathrm{K}^{+}$channels in $\mathrm{LLC}^{-\mathrm{PK}_{1}}$ cells. Am $\mathrm{J}$ Physiol 272, C737 - C743 (1997)

15 Zafari AM, Ushio-Fukai M, Akers M, Yin Q, Shah A, Harrison DG, Taylor WR and Griendling KK: Role of NADH/NADPH oxidase-derived $\mathrm{H}_{2} \mathrm{O}_{2}$ in angiotensin II-induced vascular hypertrophy. Hypertension 32, 488 - 495 (1998)

16 Capers Q 4th, Alexander RW, Lou P, De Leon H, Wilcox JN, Ishizaka N, Howard $\mathrm{AB}$ and Taylor WR: Monocyte chemoattractant protein-1 expression in aortic tissues of hypertensive rats. Hypertension 30, 1397 - 1402 (1997)

17 Grunfeld S, Hamilton CA, Mesaros S, McClain SW, Dominiczak AF, Bohr DF and Malinski T: Role of superoxide in the depressed nitric oxide production by the endothelium of genetically hypertensive rats. Hypertension 26, 854 - 857 (1995)

18 Tschudi MR, Mesaros S, Luscher TF and Malinski T: Direct in situ measurement of nitric oxide in mesenteric resistance arteries - Increased decomposition by superoxide in hypertension. Hypertension 27, 32 - 35 (1996)

19 Kerr S, Brosnan MJ, McIntyre M, Reid JL, Dominiczak AF and Hamilton CA: Superoxide anion production is increased in a model of genetic hypertension - Role of the endothelium - . Hypertension 33, 1353 - 1358 (1999)

20 Katnik C and Adams DJ: An ATP-sensitive potassium conductance in rabbit arterial endothelial cells. J Physiol (Lond) 485, 595 - 606 (1995)

21 Liu Y, Hudetz AG, Knaus H-G and Rusch NJ: Increased expression of $\mathrm{Ca}^{2+}$-sensitive $\mathrm{K}^{+}$channels in the cerebral microcirculation of genetically hypertensive rats - Evidence for their protection against cerebral vasospasm. Circ Res 82, 729 - 737 (1998)

22 England SK, Wooldridge TA, Stekiel WJ and Rusch NJ: Enhanced single-channel $\mathrm{K}^{+}$current in arterial membranes from genetically hypertensive rats. Am J Physiol 264, H1337 - H1345 (1993)

23 Kauser K and Rubanyi GM: Gender difference in endothelial dysfunction in the aorta of spontaneously hypertensive rats. Hypertension 25, 517 - 523 (1995)

24 Panza JA, Garcia CE, Kilcoyne CM, Quyyumi AA and Cannon RO III: Impaired endothelium-dependent vasodilation in patients with essential hypertension: Evidence that nitric oxide abnormality is not localized to a single signal transduction pathway. Circulation 91, 1732 - 1738 (1995) 